\title{
Trypanosoma evansi Control and Horse Mortality in the Brazilian Pantanal
}

\begin{abstract}
AF Seidl ${ }^{+}$, AS Moraes*, RAMS Silva*
Department of Agricultural \& Resource Economics, Colorado State University, Fort Collins, CO, 80523-1172, USA *Centro de Pesquisa Agropecuária do Pantanal, Empresa Brasileira de Pesquisa Agropecuária, Corumbá, MS, Brasil

The impact of three treatment strategies for Trypanosoma evansi control on horse mortality in the Brazilian Pantanal based on four size categories of cattle ranches is explored. The region's 49,000 horses are indispensable to traditional extensive cattle ranching and T. evansi kills horses. About 13\% of these horses would be lost, annually, due to T. evansi if no control were undertaken. One preventive and two curative treatment strategies are financially justifiable in the Pantanal. The best available technology for the treatment of $\mathrm{T}$. evansi from a horse mortality perspective is the preventive strategy, which spares 6,462 horses, annually. The year-round cure spares 5,783 horses, and the seasonal cure saves 5,204 horses on a regional basis relative to no control strategy. Regardless of the strategy adopted, $39 \%$ of the costs or benefits fall to the largest ranches, while $18 \%$ fall to the smallest ranches.
\end{abstract}

Key words: Trypanosoma evansi - horses - control strategies - Pantanal - Brazil

The Brazilian Pantanal is a $138,000 \mathrm{~km}^{2}$ seasonal flood plain found within the Upper Paraguay River Basin, bordering both Bolivia and Paraguay, located in the center of South America. Cattle ranching is the most important economic activity and the predominant land use in the region (Embrapa 1993). Approximately 1,100 Pantanal ranches vary in size from less than 1,000 ha to more than 200,000 ha, are populated with about 3 million head of cattle, 49,000 horses, and cover more than $80 \%$ of regional lands (Silva et al. 2001). Horses play a central role in the extensively-managed beef cattle industry.

In the Pantanal and in the subtropical regions of Argentina Trypanosoma evansi is known as "Mal de Cadeiras" (Monzon et al. 1990). The most serious outbreaks of "Mal de Cadeiras" follow extensive seasonal flooding in the region. If left untreated, certain death results from "Mal de Cadeiras" in horses within about 7 to 10 days of infection. "Mal de Cadeiras" is considered endemic to the Pantanal region (Franke et al. 1994). In the Pantanal, T. evansi has been recorded in dogs, capybaras (Hydrochaeris hydrochaeris), coatis (Nasua nasua), horses, buffalo and cattle (Stevens et al. 1989, Nunes \& Oshiro 1990, Franke et al. 1994, Silva et al. 1995b).

\footnotetext{
${ }^{+}$Corresponding author. Fax: +970-491-2067. E-mail: Andrew.Seidl@colostate.edu

Received 24 July 2000

Accepted 22 March 2001
}

Currently, ranchers in the Pantanal control the impact of trypanosomosis through treatment of existing livestock. Treatment with "pour-on" preparations is uncommon since most cases of $T$. evansi occur during the wet season when the treatment is likely to be washed off. A variety of alternative treatments and applications are employed. This study estimates the horse mortality implications of three financially justifiable control strategies for T. evansi within the Pantanal region across four ranch sizes. We build upon the results of two previous studies (Seidl et al. 1998a,b) by contributing an animal welfare perspective to these financial and policy perspectives.

\section{MATERIALS AND METHODS}

The estimated animal welfare impacts of three control strategies were compared with a "do nothing" strategy using a modified partial farm budget approach. A regional perspective is adopted, recognizing that substantial variation in results and implications would obtain at both greater and lesser spatial scales. The methodology tracks those variables common to the farm or ranch financial statement that may vary due to the disease or its control. This methodology is modified to focus upon animal welfare rather than financial considerations. Financial considerations were addressed in previously published work (Seidl et al. 1998a,b).

Improvements in animal welfare can be measured in terms of the annual number of expected deaths from T. evansi averted due to control strategies. Components of the estimated models include seasonal and annual risk prevalence, animal mor- 
tality apart from risk (Table I), the number of potentially affected horses by ranch size, and the number of ranches of each ranch size within the region (Table II). The data used for annual risk (Franke et al. 1994) were collected from the northern Pantanal and those used for seasonal risk (Silva et al. 1999) were collected from the southern Pantanal, thus inviting potential error in extrapolation to the regional level. Horse populations and ranch sizes and numbers were estimated using geopolitically determined municipality level census data, combined with geophysically delineated subregional information, operation level census information (Silva et al. 2001), and published survey research conducted in the southern Pantanal (Cadavid Garcia 1985), again creating sources of inaccuracy in calculations. More detailed information regarding the derivation of the adopted values can be found in Seidl et al. (1998a,b).

Due to data constraints and the likely spatial, temporal and individual variation in the actual values of the estimated factors, potential variations in the benefits estimates are addressed in a sensitivity analysis. This analysis explores the influence of the probable range of each variable in isolation on the estimated outcomes. Each of the models is again estimated assuming first a "high" and then a "low" value for risk prevalence, animal mortality apart from risk, and the number of potentially affected horses, each in isolation, according to the range of values found in the relevant literature.

\section{RESULTS}

No control strategy - If Pantanal ranchers choose not to control for T. evansi, the expected annual impact on the region, in horse mortality terms, can be calculated by the risk prevalence multiplied by the number of potentially exposed horses across ranch size categories. Results indicate that about $13 \%$ of the region's horses, or 6,462 animals, can be expected to die due to T. evansi if no treatment strategy is adopted.

About $39 \%$ of the horses in the Pantanal are found on 213 ranches of more than $14,400 \mathrm{ha}$. Almost $30 \%$ of the region's horses are located on 239 ranches of size 7,201-14,400 ha, while 13\% are found on 271 ranches of size 3,601-7,200 ha and $18 \%$ are on the 408 smallest size ranch category (1,000-3,600 ha) (Table II). The mean sized ranch can expect annual losses of almost six horses. Smaller ranches should expect losses of about three horses and large ranches may anticipate about 12 horse deaths per year on average. Losses are equitable relative to horse stocks across ranch size; risk of an outbreak is assumed to be equivalent for all ranches. However, larger ranches are expected to bear almost $70 \%$ of expected losses due to T. evansi outbreaks in the region (Table II).

Year round curative control strategy - The expected annual losses to T. evansi when a curative strategy is employed year-round can be calculated by multiplying the estimated risk by the estimated animal losses apart from risk and the number of horses, regionally and by ranch size. The estimated animal losses apart from risk are due to lags between diagnosis and treatment and potential ineffectiveness of the cure. These results are compared to the do nothing strategy to derive the expected benefits of control strategy adoption (Table II).

Results indicate the year round curative strategy can be expected to save 5,783 horses regionally ( $89 \%$ of anticipated annual losses), or 5.1 per ranch on average, relative to no control strategy. The largest ranches can expect to save ten or more horses on average, while the smallest ranches would benefit by two or three horses through this strategy. Analogous to no control strategy, larger ranches stand to garner almost $70 \%$ of the animal welfare benefits from the adoption of this strategy, while the smallest ranches should gain $18 \%$ of the total (Table II).

Wet season curative control strategy - About $90 \%$ of losses due to T. evansi occur during the six-month rainy season (November-April) (Silva et al. 1995a). Many ranchers monitor their herds closely only during this season. Expected annual losses to T. evansi under a seasonal curative strategy can be calculated by multiplying the wet season risk by the results of the estimated losses of the year-round strategy and adding them to the results of the do nothing strategy multiplied by the dry season risk (10\%) (Table II).

\section{TABLE I}

Components of the estimated relationships for evaluating the animal welfare impacts of control strategies for Trypanosoma evansi control in the Brazilian Pantanal

\begin{tabular}{llcccc}
\hline Variable & Published information & Value & Low range & High range & Units \\
\hline Risk of infection & Franke et al. 1994 & 13.20 & 0.30 & 56.30 & $\%$ \\
Risk-high season & Silva et al. 1995 & 90.00 & - & - & $\%$ \\
Animal losses & Seidl et al. 1998a & 10.50 & 0.00 & 51.60 & $\%$ \\
Ranches & Silva et al. 2001 & 1,131 & - & - & No. \\
\hline
\end{tabular}


TABLE II

Estimated horse losses due to Trypanosoma evansi in the Brazilian Pantanal, by control strategy and operation size

\begin{tabular}{llccccc}
\hline Operation size (ha) & & $1,000-3,600$ & $3,601-7,200$ & $7,201-14,400$ & $>14,401$ & Region \\
\hline Total & Ranches & 408 & 271 & 239 & 213 & 1,131 \\
& Horses & 8,976 & 6,233 & 14,579 & 19,170 & 48,958 \\
& Horses/ranch & 22 & 23 & 61 & 90 & 43 \\
\hline No control & Horses & 1,185 & 823 & 1,924 & 2,530 & 6,462 \\
strategy-losses & Horses/ranch & 2.9 & 3.0 & 8.1 & 11.9 & 5.7 \\
& \% of total & 18 & 13 & 30 & 39 & 100 \\
\hline Control & Year round cure-region & 1,061 & 736 & 1,722 & 2,264 & 5,783 \\
strategy-losses & Mean/ranch & 2.6 & 2.7 & 7.2 & 10.6 & 5.1 \\
avoided & Seasonal cure-region & 954 & 662 & 1,550 & 2,038 & 5,204 \\
& Mean/ranch & 2.3 & 2.4 & 6.5 & 9.6 & 4.6 \\
& Prevention-region & 1,185 & 823 & 1,924 & 2,530 & 6,462 \\
& Mean/ranch & 2.9 & 3.0 & 8.1 & 11.9 & 5.7 \\
\hline
\end{tabular}

Sources: Cadavid Garcia 1985, Silva et al. 2001

The seasonal strategy results in the preservation of 5,204 horses' lives per year on a regional basis ( $81 \%$ of expected losses), relative to no control strategy. The benefits derived from this strategy are distributed precisely as the year-round curative strategy. However, 579 horses (1\% of the regional population) are expected to die, annually, under the seasonal strategy, which would have been spared with year-round control (Table II).

Preventive treatment strategy - A preventive treatment strategy, effective in Africa, is available in nearby Bolivia and Paraguay, but is not yet registered in Brazil. If the preventive strategy is effective, no losses should be expected in its employ; risk and losses apart from risk are irrelevant. Thus, results show that 6,462 horses ( $100 \%$ of anticipated losses and 5.7 animals per ranch) per year will be saved relative to no control strategy for $T$. evansi. Again, in horse mortality or animal welfare terms, the benefits from the adoption of this strategy fall to those who have the most to gain or to lose. The largest ranches can hope to prevent the deaths of about twelve horses per year, while the smallest will expect to save about three horses per year (Table II).

Sensitivity analysis - Estimations based upon "low" and "high" potential values for risk $(0.3 \%$ and $56.3 \%)$, animal losses apart from risk $(0 \%$ and $51.6 \%)$ and the number of horses in the region $(18,240$ and 79,676$)$ do not change the distribution of horse mortality costs and benefits from each control strategy, nor do they change the ranking of each strategy on animal welfare grounds. However, the magnitude of the impact of the disease on both individual ranchers and the region varies consid- erably, potentially having implications for individual decision-making or regional policy.

In brief, the greater the risk of infection and the greater the total number of horses in the region, the greater the cost in horse lives of choosing no control strategy or either of the curative strategies over preventive control for T. evansi. If the risk of infection is very low, less than one horse per year per ranch will be lost due to the disease and little is likely to be done in terms of control. At high levels of risk, more than 24 horses per ranch per year may be lost without control and treatment could save over one half of the region's horses each year. If diagnosis and treatment are perfectly effective, there is no incentive to adopt a preventive strategy over a year-round cure. If there are large time lags or ineffectiveness in diagnosis and treatment or if the risk of infection increases, the animal welfare incentives to adopt preventive strategies become stronger (Table III).

\section{DISCUSSION}

Cattle ranching is the dominant land use in the Pantanal region of Brazil. Horses are indispensable to the traditional extensive ranching management system employed in the region. T. evansi kills horses. Control strategies for T. evansi have differential impacts on the horse population. Animal welfare incentives to control the disease vary in magnitude, but not proportionally, across ranch sizes. Understanding impact of $T$. evansi on horse mortality in the Pantanal, in conjunction with distributional and financial information, can help ranchers and policy makers to craft policies to reach individual and regional objectives most effectively. 
TABLE III

Sensitivity analysis of Trypanosoma evansi control in the Pantanal

\begin{tabular}{|c|c|c|c|c|c|c|}
\hline \multirow[t]{3}{*}{ Strategy } & \multicolumn{6}{|c|}{ Anticipated annual animal losses } \\
\hline & \multicolumn{2}{|c|}{ Risk } & \multicolumn{2}{|c|}{ Animal losses } & \multicolumn{2}{|c|}{ Horses } \\
\hline & Low & High & Low & High & Low & High \\
\hline No control & 147 & 27,563 & 6,462 & 6,462 & 2,408 & 10,517 \\
\hline Year-round cure & 15 & 2,894 & 0 & 3,335 & 253 & 1,104 \\
\hline Wet season cure & 28 & 5,361 & 646 & 3,647 & 468 & 2,046 \\
\hline Prevention & 0 & 0 & 0 & 0 & 0 & 0 \\
\hline
\end{tabular}

Left untreated T. evansi would result in the loss of $13 \%$ of the region's 49,000 horses, annually. The majority of these losses fall to the ranches with the most animals. The regional adoption of a year -round curative strategy results in the mitigation of these losses by almost $90 \%$ (5,783 horses). The most common strategy employed in the region is a curative strategy administered only during the rainy season. This strategy results in $81 \%$ fewer horse deaths than no control, but sacrifices $1 \%$ of the region's animals to the disease each year relative to the year-round strategy. The preventive strategy provides $100 \%$ protection from the disease saving more than 600 animals relative to the yearround cure. About $40 \%$ of the benefits or costs of any of the control strategies examined fall to the largest ranches, while less than $20 \%$ fall to the smallest, but most plentiful ranches. The greater the assumed risk and the greater the number of potentially infected horses, the greater the incentives are to adopt control strategies. The more inefficient the systems of diagnosis and treatment, the greater the incentives are to adopt a preventive strategy over curative control. The greater the potential for the evolution of treatment resistant strains of $T$. evansi, due to the proper or improper application of the preventive strategy, the lower the long-term attractiveness of prophylaxis.

Of course, the actual risk of infection and anticipated impact of T. evansi varies across ranches and over time. Climatic variation, ecological features of individual ranches, management factors, movement patterns of cattle and other animals, and the long term effectiveness of curative and preventive strategies against evolving sub-populations of $T$. evansi will influence the appropriateness of ranchers' and policy makers' decisions regarding the control of the disease. Rough regional estimates, based upon the best available information, were provided in order to advance the understanding of the efficacy of individual, local and regional treatment alternatives for $T$. evansi in the Brazilian Pantanal.

\section{REFERENCES}

Cadavid Garcia EA 1985. Análise Técnico-economica da Pecuária Bovina do Pantanal; Sub-regiões da Nhecolândia e dos Paiaguás, Circular Técnica 15, Embrapa, Corumbá, 16 pp.

Embrapa 1993. Plano Diretor do Centro de Pesquisa Agropecuária do Pantanal-CPAP, Ministério da Agricultura do Abastecimento e da Reforma Agrária, Empresa Brasileira de Pesquisa Agropecuária, Brasília, 32 pp.

Franke CR, Greiner M, Mehlitz D 1994. Investigations on naturally occurring Trypanosoma evansi infections in horses, cattle, dogs and capybaras (Hydrochaeris hydrochaeris) in Pantanal de Poconé (Mato Grosso, Brazil). Acta Trop 58: 159-169.

Monzon CM, Mancebo OA, Roux JP 1990. Comparison between six parasitological methods for diagnosis of Trypanosoma evansi in the subtropical area of Argentina. Vet Parasitol 36: 141-146.

Nunes VLB, Oshiro ET 1990. Trypanosoma (trypanozoon) evansi in the coati from the Pantanal region of Mato Grosso do Sul state, Brazil. Trans $R$ Soc Trop Med 33: 219-234.

Seidl AF, Moraes AS, Silva RAMS 1998a. A financial analysis of alternative strategies for treatment of Trypanosoma evansi in the Brazilian Pantanal. J Prev Vet Med 33: 219-243.

Seidl AF, Moraes AS, Silva RAMS 1998b. Distributive and region policy implications of Trypanosoma evansi control in the Pantanal, Brazil. Braz $R A g$ Econ Rur Soc 36: 309-324.

Silva J dos SV da, Moraes AS, Seidl AF 2001. Evolução da Agropecuária no Pantanal Brasileiro, 1975. 1985, Embrapa, Corumbá, in press.

Silva RAMS, Arosemena NAE, Herrera HM, Sahib CA, Ferreira MSJ 1995b. Outbreak of trypanosomosis due to Trypanosoma evansi in horses of Pantanal Matogrossense, Brazil. Vet Parisitol 60: 167-171.

Silva RAMS, Barros ATM, Herrera HM 1995a. Foyers trypanosomiens dus a Trypanosoma dan le Pantanal, Bresil. Une approche preliminaire sur les facteurs de risque. Revue Elev Méd Vét Pays Trop 48: 315 319.

Stevens JR, Nunes VLB, Lanham SM, Oshiro ET 1989. Isoenzyme characterization of Trypanosoma evansi isolated from capybaras and dogs in Brazil. Acta Trop 46: 213-222. 